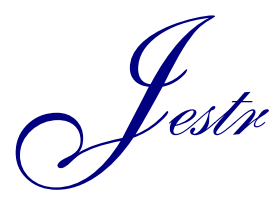

Journal of Engineering Science and Technology Review 11 (3) (2018) 42 - 49

Research Article

www.jestr.org

\title{
Elastic-Plastic Behavior of Circular Hollow Section Steel Tubes Subjected to Bending
}

\author{
Amer M. Ibrahim and Manahel Shahath Khalaf* \\ Department of Civil Engineering, Diyala University, Diyala, Iraq
}

Received 3 January 2018; Accepted 18 July 2018

\begin{abstract}
Steel circular hollow sections (CHSs) are widely used in the mechanical and construction applications. These sections are mainly subjected to bending moment that caused by lateral loads. This paper aims to investigate the elastic-plastic behavior of steel circular hollow sections under bending loading. The experimental work of this study included a series of bending tests to examine and determine the influence of the section thickness, diameter and beam span on the structural behavior of steel tubes. In addition, the influence of the presence and number of square openings on the behavior of these sections was studied. Ten circular hollow beam specimens were performed and tested up and post of failure stage with different section thickness, diameter and specimen span. The experimental results showed that increasing the specimen section thickness improved the structural strength capacity and the specimen ability to absorb and dissipate energy and prevented the sudden or rapid failure. While increasing the section diameter increased the structural strength capacity significantly, but it had a negative impact on the specimen ability to absorb energy that caused the sudden failure for the specimen. Decreasing the specimen span increased the structural strength capacity, but reduced the specimen ability to absorb energy.
\end{abstract}

Keywords: Circular hollow section, Steel tubes, Bending, Local buckling

\section{Introduction}

In recent years, the steel structures have become more popular as construction applications therefore attracted many of research efforts to study the strength and structural behavior of steel sections.

Development of steel in construction structures led to increase the varieties of steel sections that are used as a construction materials. One type of these sections is the circular hollow section (CHS) which is considered one of the most reliable sections due to the following reasons:

- CHSs have many excellent properties as a structural element in resistance to bending, axial and torsion. This is due to the uniform distributed of the cross section materials about the polar axis [1].

- For tall bridge structure, it is often used the CHS in their construction because it is working to decrease their mass and thus reducing the self-weight that contribute in vibration during earthquake [2].

- CHS gives the building a better ratio of strength to weight which lead to reduce the using of materials and allow for greater span buildings [3].

- The internal void of CHSs gives possibility for the combination between the strength function and the other functions such as fire protection, heating and ventilation systems [3].

- The CHS offers many advantages in relation to protection against corrosion because of the CHSs

*E-mail address: manahelshahath@gmail.com

ISSN: $1791-2377$ @ 2018 Eastern Macedonia and Thrace Institute of Technology. All rights reserved.

doi:10.25103/jestr.113.06 have rounded edges and smaller surface area than the open sections. The closed shape of these sections and the smooth change from one to another at the joints minimize the corrosion protection costs [4].

The behavior of steel circular hollow sections when subjected to bending is affected by the local buckling. In order to identify the influence of the local buckling on the circular hollow sections bending behavior, the steel specifications define cross-section as different classes depending on the point at which the local buckling occurs during the bending [5]. In the AISC-LRFD and AS4100 codes, the cross sections are classified as compact, noncompact and slender section $[6,7]$.

In the past, many experimental studies on CHSs were conducted by researchers [8-11]. These studies mainly focused on the effect of the section slenderness ratio on the bending properties for CHSs. The experimental work of these studies included testing of many specimens with diameter to thickness ratio ranging from 16 to 122 . Three kinds of loading types are commonly used to study the bending behavior of steel tubes, i.e., the simply-supported beam test, the cantilever beam test and the pure bending beam test.

\section{Experimental work}

\subsection{Design and fabrication of CHS specimens}

In order to study the bending behavior of steel circular hollow specimens, the experimental program included testing of ten beam specimens up and post of failure stage by 
using different sizes for circular sections. These specimens were distributed into four different groups as the following:

\section{First group}

The primary variable of this group is the section thickness. This group included testing of three specimens that are different in their thickness with the same span and diameter as shown in Tab. 1.

Table 1. First group specimens

\begin{tabular}{c|c|c|c}
$\begin{array}{c}\text { Specimen } \\
\text { No. }\end{array}$ & $\begin{array}{c}\text { Thickness } \\
\text { mm }\end{array}$ & $\begin{array}{c}\text { Diameter } \\
\text { mm }\end{array}$ & $\begin{array}{c}\text { Span } \\
\text { mm }\end{array}$ \\
\hline BT1 & 3 & 101.6 & 1500 \\
BT2 & 2 & 101.6 & 1500 \\
BT3 & 6 & 101.6 & 1500 \\
\hline
\end{tabular}

\section{Second group}

The primary variable of this group is the presence of the openings. This group included testing of four specimens that are different in openings number and their existence locations in the specimen and with the same span, diameter and thickness as shown in Tab. 2.

Table 2 Second group specimens

\begin{tabular}{c|c|c|c|c}
\hline $\begin{array}{c}\text { Specimen } \\
\text { No. }\end{array}$ & $\begin{array}{c}\text { Thickness } \\
\mathbf{m m}\end{array}$ & $\begin{array}{c}\text { Diameter } \\
\mathbf{m m}\end{array}$ & $\begin{array}{c}\text { Span } \\
\mathbf{m m}\end{array}$ & $\begin{array}{c}\text { Openings } \\
\text { No. }\end{array}$ \\
\hline BT1 & 3 & 101.6 & 1500 & Without \\
BT4 & 3 & 101.6 & 1500 & One \\
BT5 & 3 & 101.6 & 1500 & Two \\
BT6 & 3 & 101.6 & 1500 & Three \\
\hline
\end{tabular}

\section{Third group}

The primary variable of this group is the span of the specimen. This group included testing of three specimens that are different in their span as shown in Tab. 3.

Table 3 Third group specimens

\begin{tabular}{c|c|c|c}
\hline $\begin{array}{c}\text { Specimen } \\
\text { No. }\end{array}$ & $\begin{array}{c}\text { Thickness } \\
\mathbf{m m}\end{array}$ & $\begin{array}{c}\text { Diameter } \\
\mathbf{m m}\end{array}$ & Span $\mathbf{m m}$ \\
\hline BT1 & 3 & 101.6 & 1500 \\
BT7 & 3 & 101.6 & 2000 \\
BT8 & 3 & 101.6 & 1000 \\
\hline
\end{tabular}

\section{Fourth group}

The primary variable of this group is the section diameter. This group included testing of three specimens that are different in their diameter as shown in Tab. 4.

Table 4. Fourth group specimens

\begin{tabular}{c|c|c|c}
\hline $\begin{array}{c}\text { Specimen } \\
\text { No. }\end{array}$ & $\begin{array}{c}\text { Thickness } \\
\text { mm }\end{array}$ & $\begin{array}{c}\text { Diameter } \\
\text { mm }\end{array}$ & Span mm \\
\hline BT1 & 3 & 101.6 & 1500 \\
BT9 & 3 & 219 & 1500 \\
BT10 & 3 & 76.2 & 1500 \\
\hline
\end{tabular}

The steel tubes when subjected to bending moment, a deformation will happen in their cross-section which leads to the occurrence of the ovalisation phenomenon for circular sections. Increasing the bending moment will cause gradual growth of the ovalisation phenomenon and thus lead to a gradual decrease in the bending rigidity of the specimen. When the value of the ovalisation reaches to the critical value, the circular hollow specimens will be subjected to the local buckling.
Therefore, it is important to create special conditions at the loading points of the specimen to prevent the early development of the ovalisation phenomenon at the loading points and restrain the circular section. In order to achieve this, four steel circular rings were used in the experimental study that were mounted the specimen at the supports and two loading points. Each ring is composed of two semicircular pieces with thickness equal to $35 \mathrm{~mm}$ connected to each other by bolts as shown in Fig. 1 .

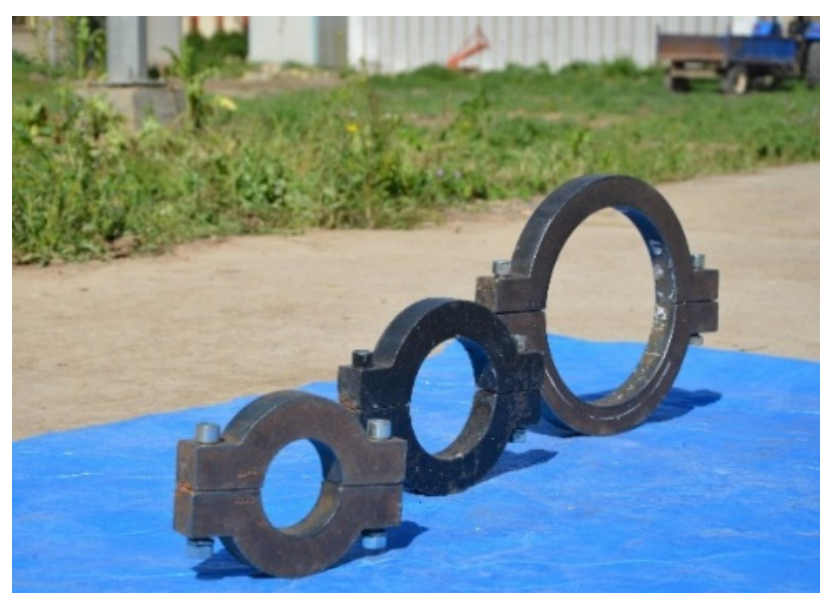

Fig. 1. Steel circular rings

\subsection{Experimental setup}

The experimental study used the four-point bending test in order to test the specimens, the specimen placed between two supports as shown on Fig. 2. The vertical load was applied on the center of the specimen by using the hydraulic jack, which was associated with the load cell and attached to the spreader beam. After that the applied load was transferred equally to the specimen at two loading points through the spreader beam.

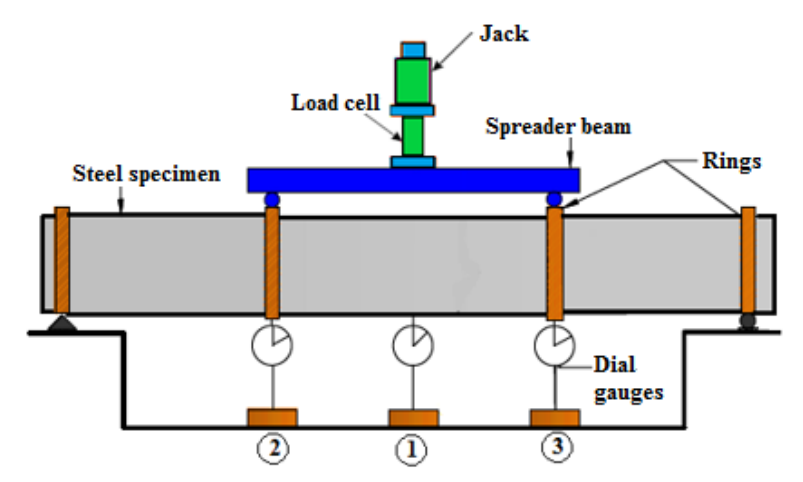

Fig. 2. Schematic view of test device

Three dial gauges were used in this study. These gauges were installed at the loading points and at the mid-span to measure the vertical deflection at these locations.

\section{Analysis of experimental results}

\subsection{Load- deflection relationship curve}

The structural behavior of steel circular hollow specimens when subjected to bending characterized by three different stages with increasing the applied load, these stages are: 


\section{The elastic stage}

This stage starts from the beginning of loading and continues until it access to the yield load. This stage is characterized by a linear relationship between the applied load and the specimen deflection as shown in Fig. 3, 4, 5 and 6.

\section{The ovalisation stage}

This stage represents the beginning of the specimen plastic behavior. Here, a little increase occurred in the applied loads compared with the high increase in the specimen deflection and this continued until it was reaching to the ultimate load.

Fig. 3 shows that the ovalisation stage of the specimens BT1 and BT3 was larger than that of the specimen BT2 because of increasing the thickness of specimens BT1 and BT3 caused increase the strain hardening capacity for these specimens that led to increase the stresses redistribution significantly until they were access to the ultimate load.

Fig. 4 shows that the ultimate load value of the specimens BT4, BT5 and BT6 decreased by $17.88 \%$, $19.71 \%$ and $14.23 \%$ respectively compared with the specimen BT1. From this, it can be noted that the presence of the openings effected significantly on the ovalisation stage through reduction the strain hardening capacity that led to a significant reduction in the specimens stresses redistribution compared with the specimen BT1.

Fig. 5 shows that the ultimate load value of the specimens BT7 and BT8 equal to $53 \mathrm{kN}$ and $104 \mathrm{kN}$ respectively, this is due to that the specimen span is inversely proportional to the loads carrying capacity of the specimen. While from Fig. 6, it can be observed that the ultimate strength capacity directly proportional to the specimen dimeter therefore, the specimens with large diameter BT1 and BT9 possessed high strength compared with the specimen BT10.

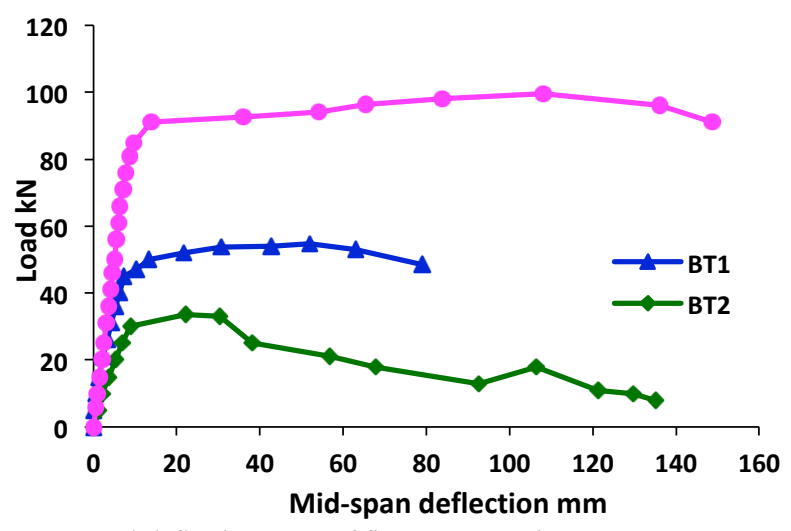

Fig. 3. Load-deflection curve of first group specimens

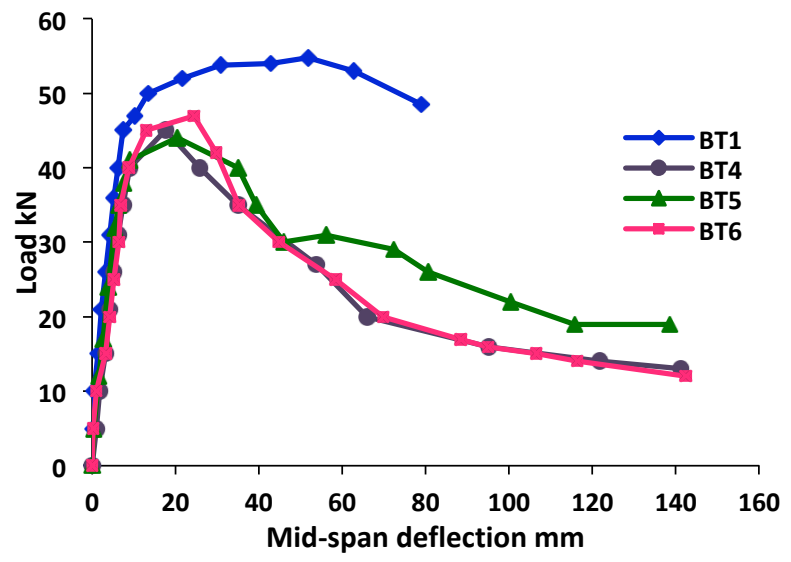

Fig. 4 Load-deflection curve of second group specimens

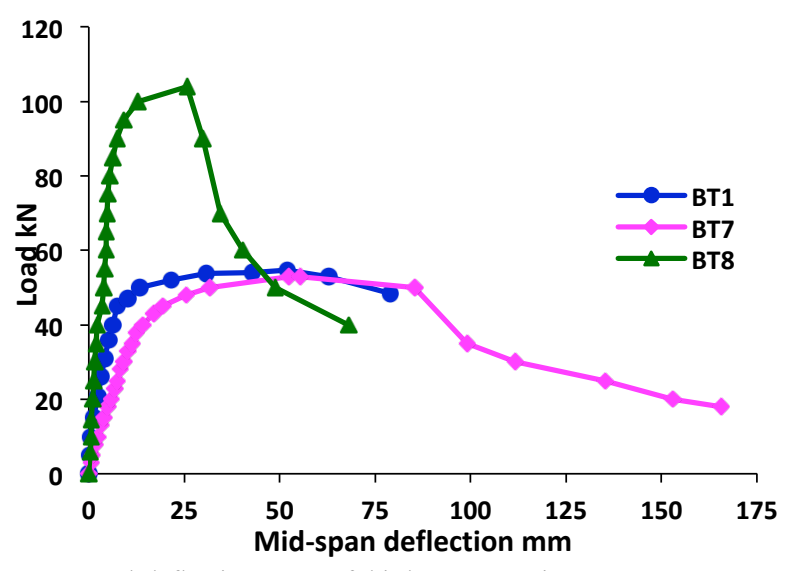

Fig. 5. Load-deflection curve of third group specimens

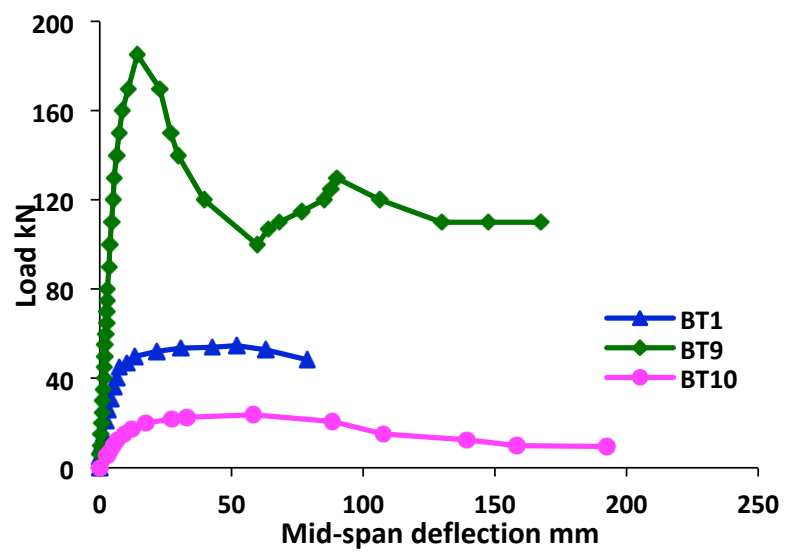

Fig. 6. Load-deflection curve of fourth group specimens

3. The structural collapse stage

This stage starts at the ultimate load and refers to the failure of the specimens. The collapse of the specimen BT1 began through very smooth kink forming in the compression part at pure bending region. Continuation the specimen load led to gradual growth of this kink and thus caused the local buckling in the specimen top surface as shown in Fig. 7. While the collapse of the specimen BT2 began through appearance of wave buckling in the specimen top part of the mid-span region as shown in Fig. 8.

The collapse of the specimen BT3 started by increasing the specimen deformation at the ultimate load without appearance any buckling. The applied loads on this specimen led to high curvature for the specimen central region as shown in Fig. 9.

From the first group specimens, it can be noted that increasing the specimen thickness improved the specimen loads carrying capacity significantly and changed the class of the cross-section from non-compact section in the specimen BT2 to compact section in the specimen BT1 and the plastic section in the specimen BT3, thus influenced on the specimen structural collapse through change the failure mode from the wave buckling in the specimen BT2 to formation of smooth kink in the specimen BT1 and increasing the curvature of the specimen BT3 without appearance of any buckling.

The collapse of the specimen BT4 began by the occurrence of high plastification in the top surface of the opening which led to the kink formation in this surface. After that, this kink has evolved into the local buckling and moved from the top surface of the opening to the top surface of the specimen causing the formation of two folds, one in 
the top surface and the other in the bottom surface and finally led to the global buckling failure mode as shown in Fig. 10. While the collapse of the specimen BT5 began by the fold formation in the top surface of the specimen at opening in the left loading point. The continuation of the specimen loading beyond the ultimate load has led to increase the amplitude and height of the fold without occurrence of transmission to other places as shown in Fig. 11. Fig. 12 shows the collapse of the specimen BT6 which began through exposed the top surface of the central opening to large deformation that led to the local buckling formation in the specimen top surface.

From the second group specimens, it can be noted that the structural behavior and the yield and ultimate load values of the specimens BT4, BT5 and BT6 didn't affect by changing the number of openings in the pure bending region because these openings are located at the cross-section neutral axis and thus it had a small effect on the structural behavior. On the other hand, the openings within each specimen are racing with each other in order to reach the ultimate load, and the opening that reaches firstly will control the specimen and cause the structural failure of it.

The structural collapse stage of the specimen BT7 began at the ultimate load through increasing the specimen deflection that leading to increase the curvature of the top and bottom surface of the specimen. Continuation of the specimen loading led to the formation of smooth kink in the top surface of the specimen central part as shown in Fig. 13. While for the specimen BT8, this stage began by the fold formation in the top part of the specimen and adjacent to the right loading ring when applied the ultimate load accompanied by a few increase in the specimen deflection. Continuing the specimen loading led to the development of this fold and finally led to the local buckling failure in the compression part as shown in Fig. 14.

From the third group specimens, it appears that increasing the specimen span changed the type of the specimen failure from the local buckling in the specimen BT8 to the global buckling through kink formation in the specimens BT1 and BT7.

The collapse of the specimen BT9 began when applied the ultimate load through a fold (outwards bulge) formation the compression part of the specimen cross-section adjacent to the right loading point ring. Continuing the specimen loading worked to the development of this fold and increase its amplitude without transfer it to other places. At load equal to $100 \mathrm{kN}$ (beyond the ultimate load), redistribution of the specimen stresses occurred because of the high strain hardening capacity of this specimen which led to increase the specimen capacity from $100 \mathrm{kN}$ to $130 \mathrm{kN}$. After that, a reduction in the loads carrying capacity occurred because of the formation of another fold in the specimen cross-section adjacent to the left loading point ring. These folds continued to evolve with applied loads until they became almost at the same level as shown in Fig. 15, which finally led to the local buckling failure in the compression part and outside the central span region. Fig. 16 shows the collapse of the specimen BT10 that began by the formation of smooth kink in the compression part of the central span region.

From the fourth group specimens, it appears that decreasing the specimens diameter from (219 to 101.6 and 76.2) $\mathrm{mm}$ changed the class of the cross-section from noncompact section in the specimen BT9 to the compact section in the specimens BT1 and BT10, and thus changed the failure mode for these specimens from the local buckling to the global buckling.

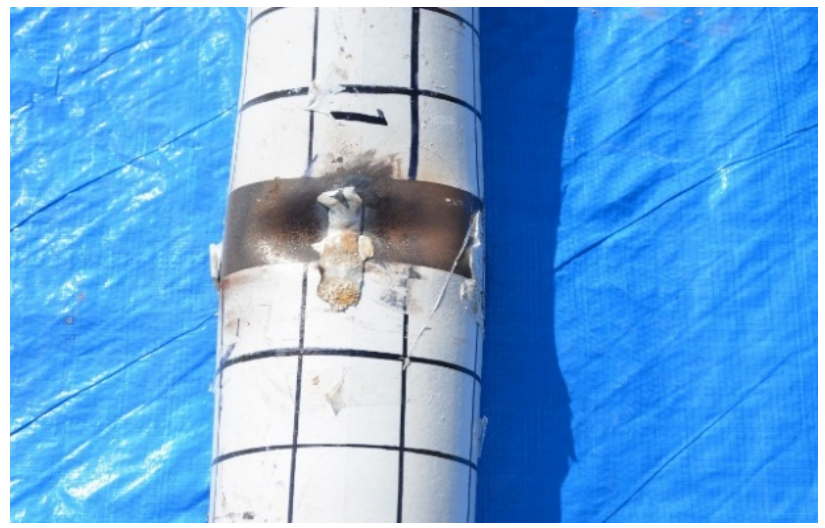

Fig. 7. Structural failure of specimen BT1

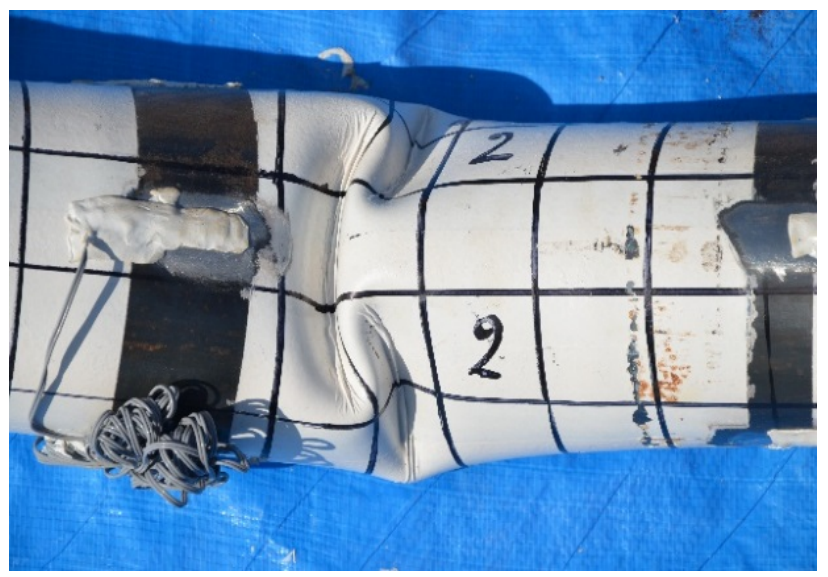

Fig. 8 Structural failure of specimen BT2

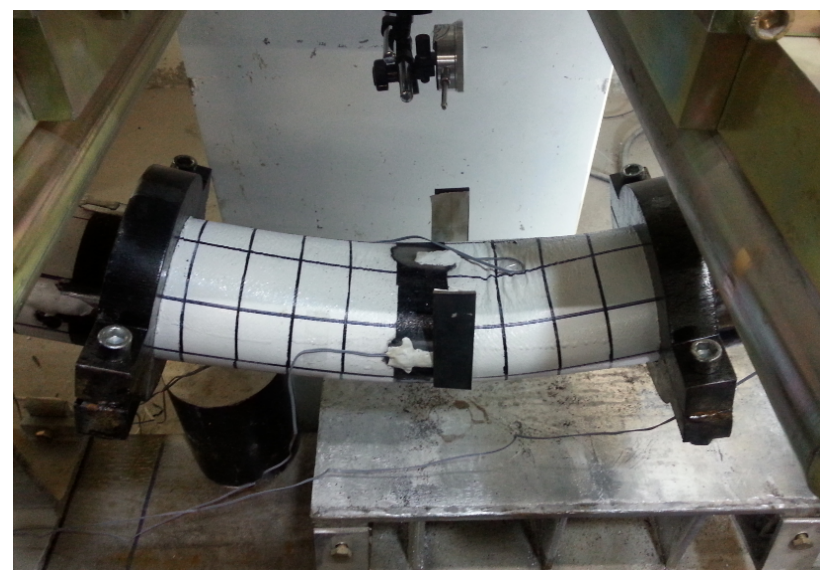

Fig. 9 Structural failure of specimen BT3

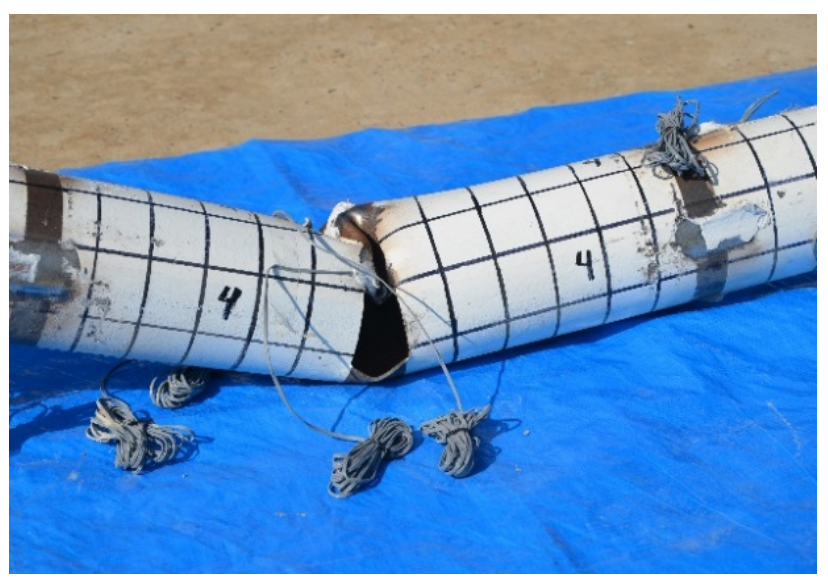

Fig. 10. Structural failure of specimen BT4 


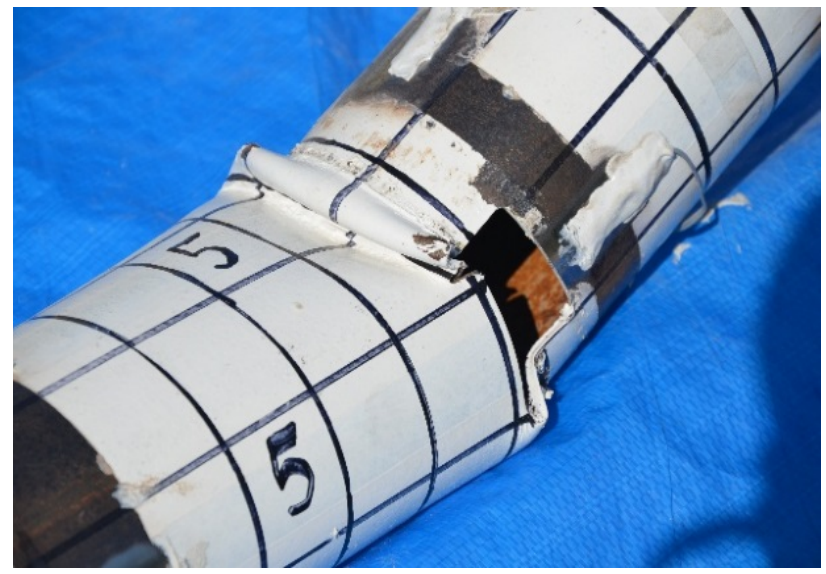

Fig. 11. Structural failure of specimen BT5

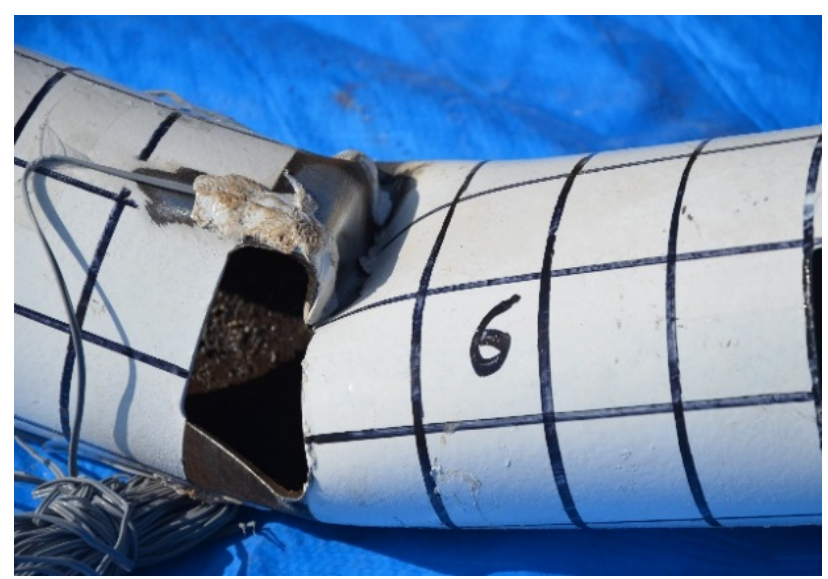

Fig. 12 Structural failure of specimen BT6

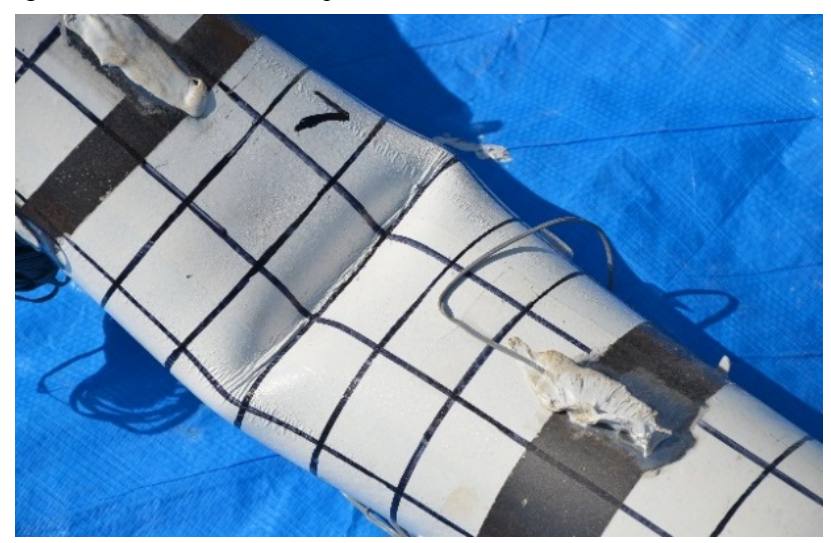

Fig. 13 Structural failure of specimen BT7

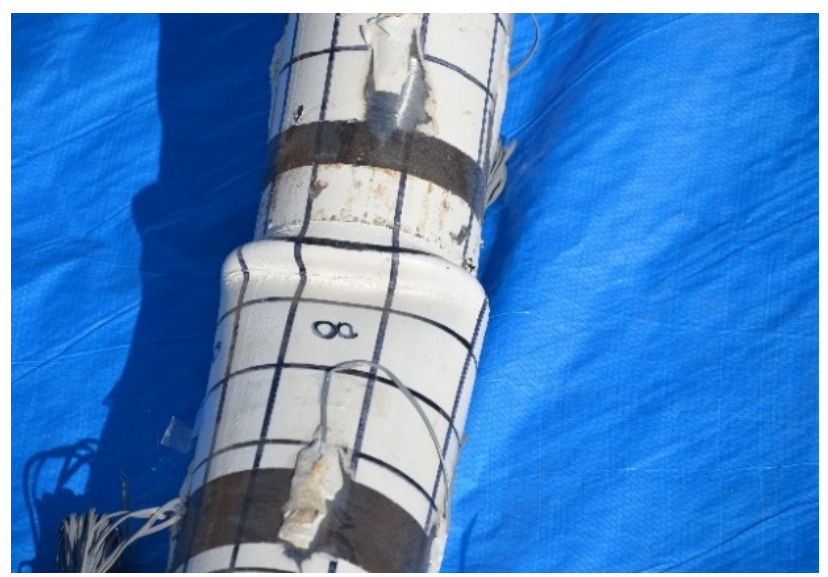

Fig. 14 Structural failure of specimen BT8

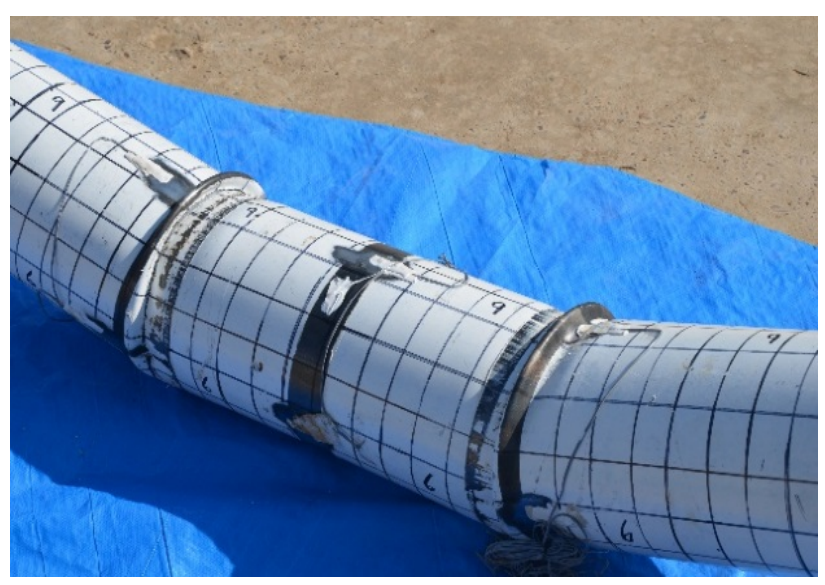

Fig. 15 Structural failure of specimen BT9

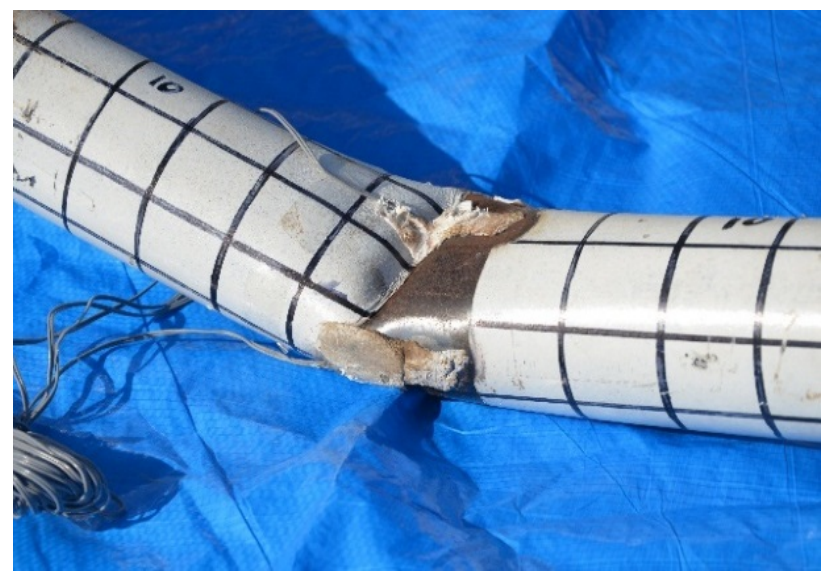

Fig. 16 Structural failure of specimen BT10

\subsection{Ductility}

It is one of the important mechanical properties of the steel specimens, which is a measure of degree of the specimen plastic deformation. The value of the specimen ductility is obtained from the division of the ultimate deflection at midspan on the yield deflection. The ductility values of test specimens are shown in Fig. 17, 18, 19 and 20.

Fig. 17 shows that the specimen BT2 has a low ductility up to 2.47 as a result of the low deflection value at the ultimate load and this caused the sudden and rapid drop in the loads carrying capacity when it was access to the ultimate load. The specimen BT1 has ductility value up to 7.03 and it was due to the high value of the deflection at the ultimate load compared with the deflection value at the yield load and thus caused a gradual drop in the specimen loads capacity. While the value of the ultimate deflection of specimen BT3 was high and caused increasing the specimen ductility significantly which equaled to 11.11 , this ductility led to a gradual and flat drop in the specimen loads carrying capacity.

From Fig. 18, it is found that the presence of openings in the specimens BT4, BT5 and BT6 reduced their ductility significantly by $72.40 \%, 67.71 \%$ and $60.88 \%$ respectively compared with the specimen BT1. This is due to the high reduction in the values of the ultimate deflection for these specimens therefore, it was observed sudden and rapid drop in the loads carrying capacity of these specimens when they reached to the ultimate load compared with the gradual drop of the specimen BT1.

Fig. 19 gives the ductility values of the third group specimens. From this figure, it can be noted that the 
specimen BT8 has a low ductility compared with the specimen BT1 which equal to 3.50 as a result of the low value of the specimen deflection at the ultimate load. While the values of the deflection of specimen BT7 at both the yield and ultimate load were high and this caused in making the value of the specimen ductility moderate and equal to 4.42 therefore, it was responsible for the gradual drop in this specimen loads capacity.

Increasing the diameter of the specimens affected on their ductility as shown in Fig. 20. This figure shows that the ductility of the specimen BT9 was very little and reached to 1.64 because of the small deflection at the ultimate load. This few ductility caused the sudden drop in the specimen loads capacity. While the specimen BT10 had high deflection values at each of the yield and ultimate load which made the specimen ductility of moderate value reached 4.80 and caused the gradual drop of the loaddeflection curve after the ultimate load.

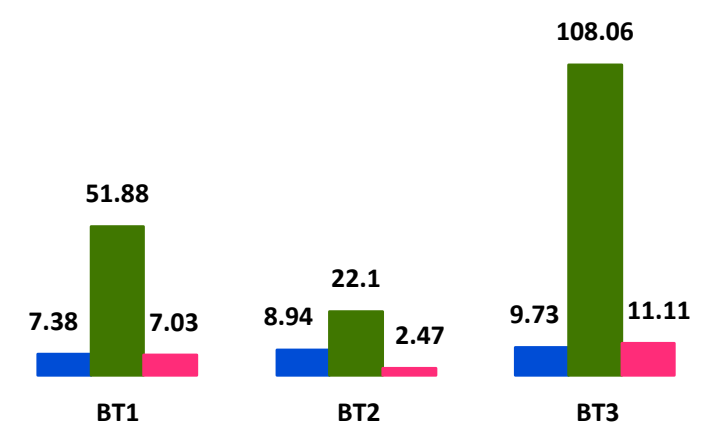

Yield deflection $\mathrm{mm}$ Ultimate deflection $\mathrm{mm}$ Ductility

Fig. 17 Test results of first group specimens

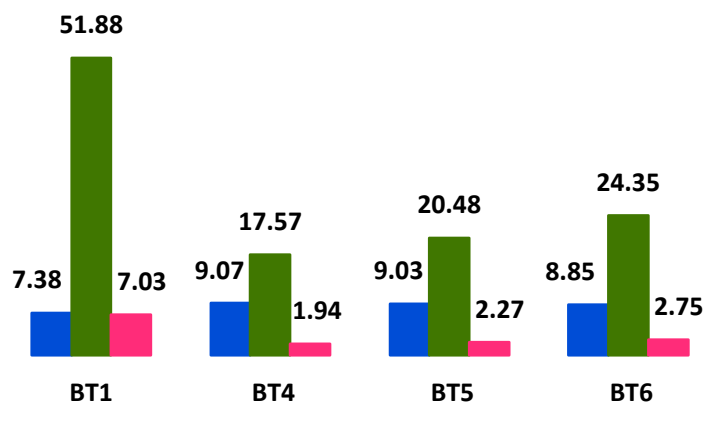

Yield deflection $\mathrm{mm}$ Ultimate deflection $\mathrm{mm}$ Ductility

Fig. 18 Test results of second group specimens

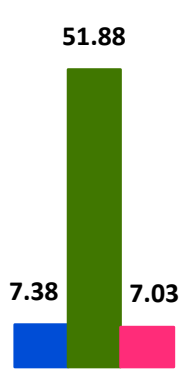

BT1

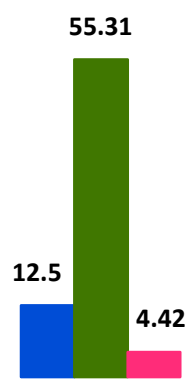

BT7

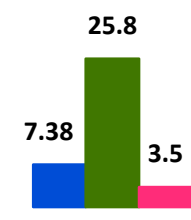

BT8 $\square$ Yield deflection $\mathrm{mm}$ Ultimate deflection $\mathrm{mm}$ Ductility

Fig. 19 Test results of third group specimens

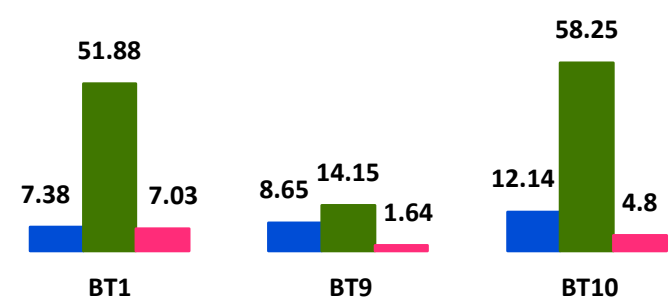

Yield deflection $\mathrm{mm}$ Ultimate deflection $\mathrm{mm}$ Ductility

Fig. 20 Test results of fourth group specimens

\subsection{Deflection profile}

The comparison of deflection profile for first group specimens BT1, BT2 and BT3 at yield and ultimate load is shown in Fig. 21. Under the influence of yield load, the specimen BT3 showed more response at the mid-span compared with the specimens BT1 and BT2. At this load, the maximum deflection of specimen BT3 increased by $31.84 \%$ from the deflection of specimen BT1. The specimen BT2 followed the specimen BT3 in its response and increased the value of maximum deflection by $21.14 \%$ from the corresponding deflection of specimen BT1. While the specimen BT1 gave the less response at this load.

At the ultimate load, the first group specimens behaved in a similar way but differed in their deflection values. The specimen BT3 showed a very high increase in its deflection and gave a value of maximum deflection equaled to 108.6 $\mathrm{mm}$ which is nearly twice the maximum deflection of specimen BT1. While the specimen BT2 showed less response at this load and its maximum deflection value decreased by $57.40 \%$ from the maximum deflection of specimen BT1.

From deflection profile of first group specimens, it can be noted that under the influence of the ultimate load, increasing the specimens thickness led to increase their ability to absorb and dissipate energy and increase the specimen resistance to failure and thus delay the failure of these specimens.

The Fig. 22 gives a comparison of deflection profile for second group specimens BT1, BT4, BT5 and BT6. At the yield load, the specimens BT5 and BT6 showed the similar behavior and gave the maximum deflection at the left loading point which equaled to $10.20 \mathrm{~mm}$ and $9.51 \mathrm{~mm}$ respectively. While the maximum deflection of specimen BT4 was at the mid-span point and reached $9.07 \mathrm{~mm}$.

At the ultimate load, the specimens BT1, BT4 and BT6 showed a similar behavior but differed in their deflection values. The specimen BT1 showed the most response at the mid-span compared with the remaining specimens and the value of maximum deflection for this specimen reached to $51.88 \mathrm{~mm}$. While the maximum deflection of the specimens BT4 and BT6 was $34 \%$ and $47 \%$ respectively from the corresponding deflection of specimen BT1. The specimen BT5 showed more response at left loading point and gave deflection at mid-span reached to $40 \%$ from the deflection of specimen BT1.

From deflection profile of second group specimens, it can be observed that the presence of openings reduced the ability of the specimens BT4, BT5 and BT6 to energy absorption and reduced their resistance to fracture and finally accelerate the specimens failure unlike the specimen BT1 which characterized by its ability to resistance the failure. 
The Fig. 23 compares the deflection profile for the third group specimens BT1, BT7 and BT8. Under the influence of yield load, the specimen BT7 gave high response compared with the specimens BT1 and BT8 and the maximum deflection value of this specimen increased by $69.38 \%$ from the corresponding deflection of specimen BT1. While the maximum deflection of specimen BT8 was equal to the deflection of specimen BT1.

At the ultimate load, the specimens BT1, BT7 and BT8 showed a similar behavior but differed in their deflection values. The specimen BT7 attained a high increase in its deflection and gave a value of the maximum deflection equaled to $55.31 \mathrm{~mm}$. While the specimen BT8 gave less response at this load and its maximum deflection value decreased by $50.27 \%$ from the maximum deflection of specimen BT1.

From deflection profile of third group specimens, it can be observed that increasing the span of the specimens worked to increase the ability of these specimens to absorption and dissipation energy and also increased the specimens resistance to fracture.

The deflection profile of the fourth group specimens BT1, BT9 and BT10 is shown in Fig. 24. At the yield load, the specimen BT10 showed a high response and the value of maximum deflection at mid-span increased by $64.50 \%$ from the corresponding deflection of specimen BT1. While the specimen BT9 gave a reading of deflection at the same location equaled to $8.65 \mathrm{~mm}$.

At the ultimate load, the specimens BT1 and BT10 behaved in a similar way. The specimen BT10 showed more response and increased the maximum deflection at mid-span by $12.28 \%$ compared with the deflection of specimen BT1. The specimen BT9 showed less response at this load and reduced its deflection at mid-span by $72.73 \%$ from the deflection of specimen BT1.

From the deflection profile of fourth group specimens, it can be noted that increasing the specimens diameter reduced their ability to absorb and dissipate energy and their resistance to fracture and eventually precipitated the failure of these specimens.
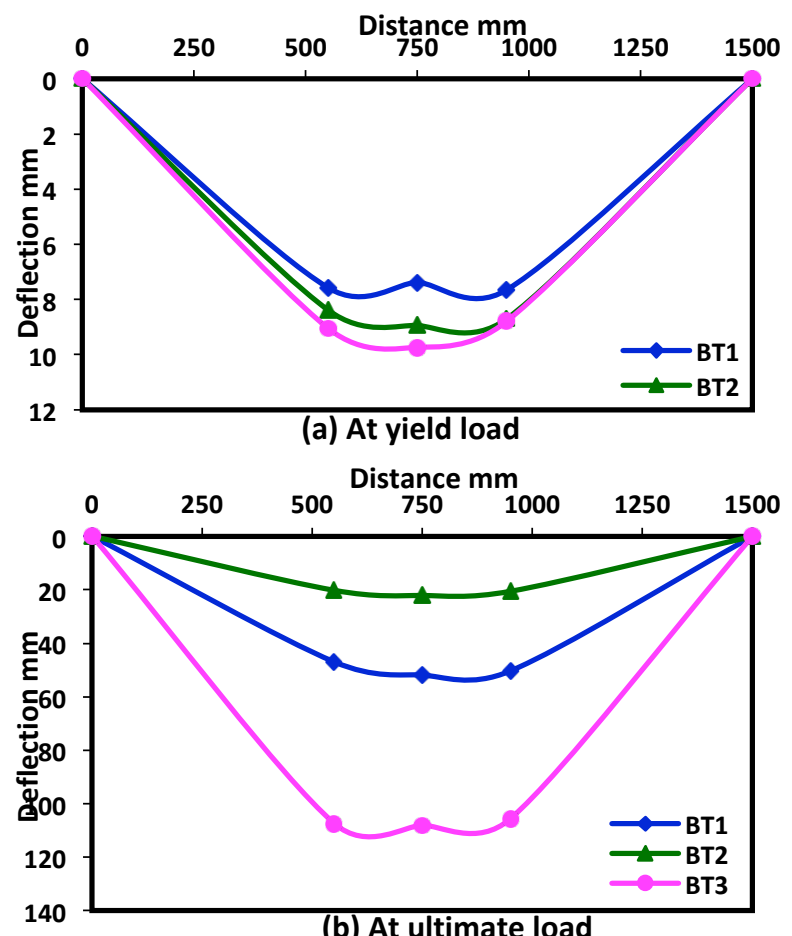

(b) At ultimate load

Fig. 21 Deflection profile for first group specimens
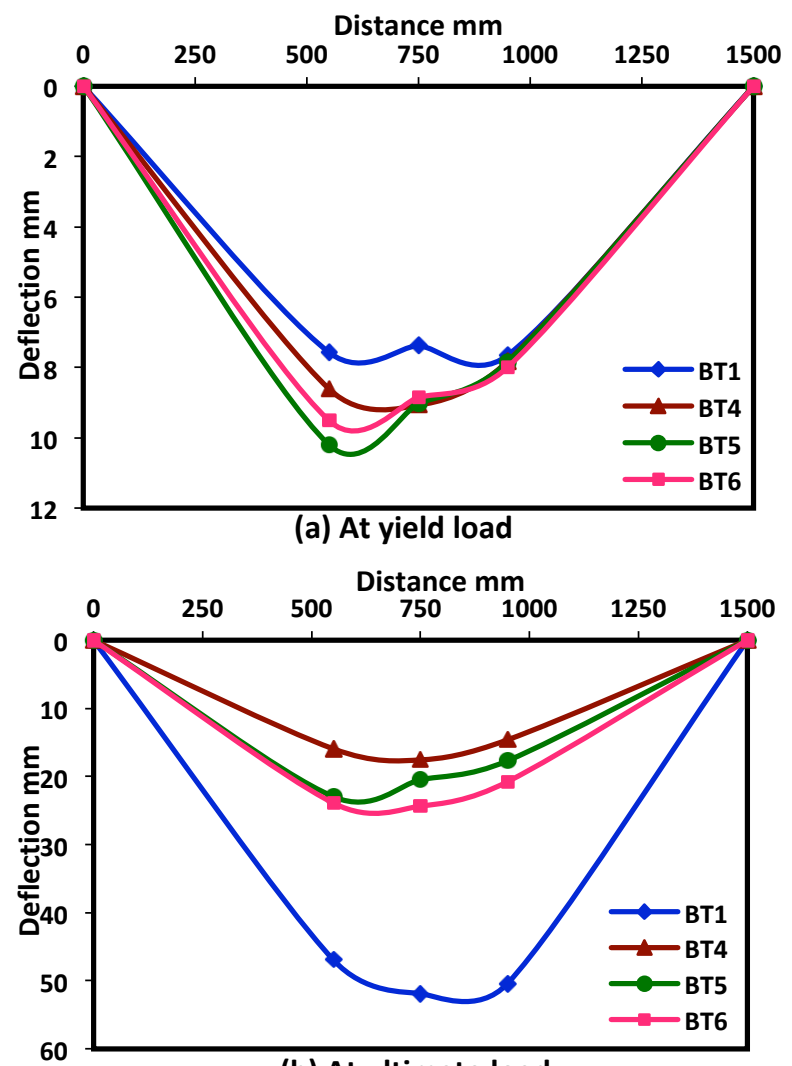

(b) At ultimate load

Fig. 22 Deflection profile for second group specimens

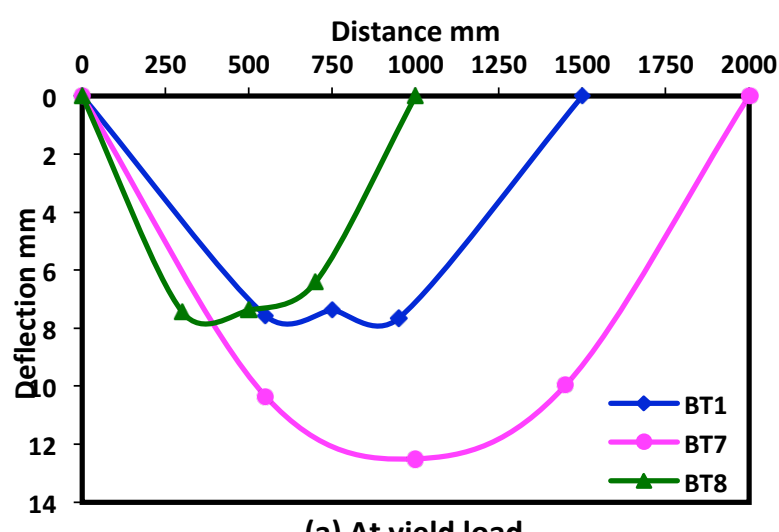

(a) At yield load

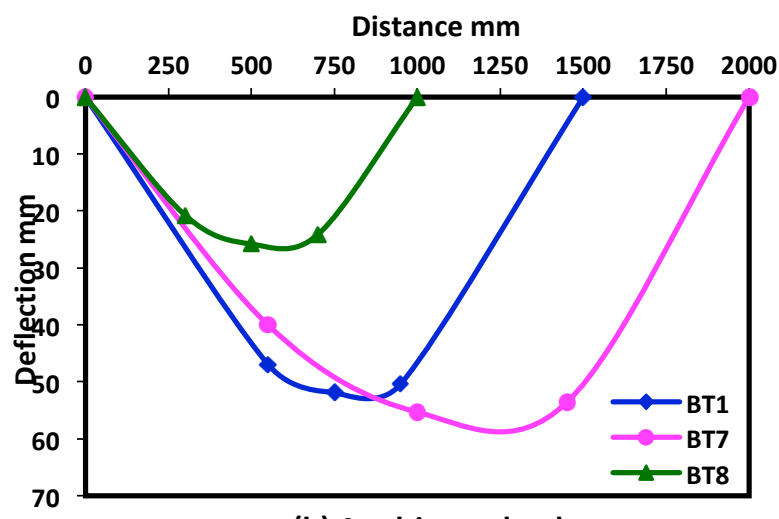

(b) At ultimate load

Fig. 23 Deflection profile for third group specimens 


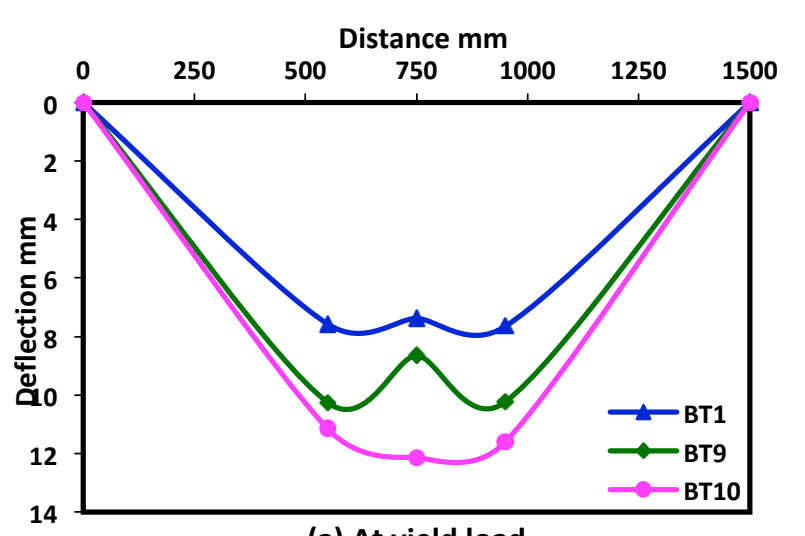

(a) At yield load
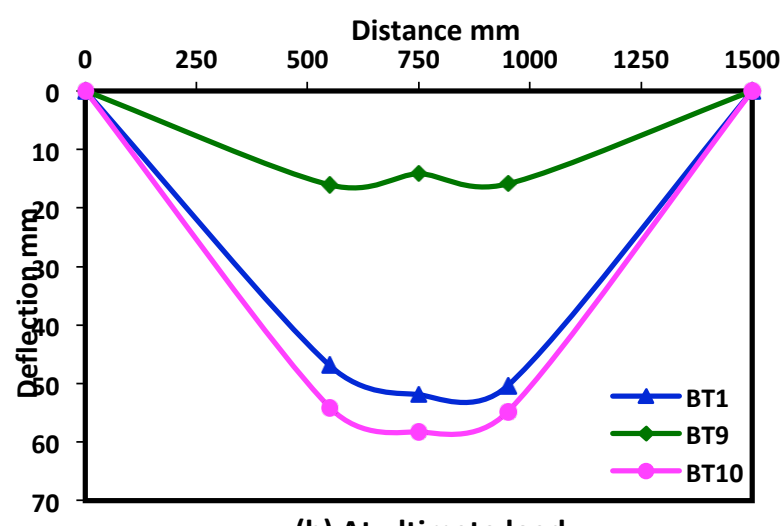

(b) At ultimate load

Fig. 24 Deflection profile for fourth group specimens

\section{Conclusions}

Based on the experimental tests results that conducted in this paper, the following conclusions are set:

1. Increasing the specimen thickness to twice improved the structural strength capacity and ductility by $81.75 \%$ and $58.04 \%$ respectively.

2. Decreasing the specimen thickness by $33.33 \%$ reduced the structural strength capacity and ductility by $38.87 \%$ and $64.86 \%$ respectively.

3. Increasing the specimen diameter by $115.55 \%$ increased the structural strength capacity by $237.59 \%$, but it reduced the specimen ductility by $76.67 \%$.

4. Decreasing the specimen diameter by $25 \%$ reduced the structural strength capacity by $56.75 \%$.

5. Increasing the specimen span by $33.33 \%$ reduced the structural strength capacity and ductility by $3.28 \%$ and $37.13 \%$ respectively. While decreasing the specimen span by $33.33 \%$ improved the structural strength capacity by $89.78 \%$, but it reduced the specimen ductility by $50.21 \%$.

6. The presence of one, two or three square openings in the specimen caused a reduction in the structural strength capacity by $17.88 \%, 19.71 \%$ and $14.23 \%$ respectively and also reduced the specimen ductility by $72.40 \%, 67.71 \%$ and $60.88 \%$ respectively.

This is an Open Access article distributed under the terms of the Creative Commons Attribution License

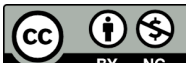

\section{References}

[1] Chavan, V. B., Nimbalkar, V. N., and Jasiwal, A. P. (2014). "Economic evaluation of open and hollow structural sections in industrial trusses". International Journal of Innovative Research in Science, Engineering and Technology, 3(2): 9554-9565.

[2] Hoshikuma, J. I., and Priestley, M. J. N. (2000). "Flexural behavior of circular hollow columns with a single layer of reinforcement under seismic loading". SSRP, 13.

[3] Wardenier, J., Packer, J. A., Zhao, X. L., and Van der vegte, G. J. (2002). "Hollow sections in structural applications". Rotterdam, The Netherlands: Bouwen met staal.

[4] Agarwal, D. S., and Chhatwani, A. C. (2015). "The economic and structural analysis of hollow structural sections". International Journal on Recent and Innovation Trends in Computing and Communication, 3(2): 57-62.

[5] Guo, L., Yang, S., and Jiao, H. (2013). "Behavior of thin-walled circular hollow section tubes subjected to bending". Thin-Walled Structures, 73: 281-289.

[6] ANSI/ AISC 360-10. (2010). "Specification for structural steel buildings". American Institute of Steel Construction.
[7] SAA Steel Structures code. (2012). "AS4100 Standards Association of Australia".

[8] Lee, K. L., Pan, W. F., and Kuo, J. N. (2001). "The influence of the diameter-to-thickness ratio on the stability of circular tubes under cyclic bending". International Journal of Solids and Structures, 38(14): 2401-2413.

[9] Elchalakani, M., Zhao, X. L., and Grzebieta, R. H. (2002). "Plastic slenderness limits for cold-formed circular hollow sections". Australian Journal of Structural Engineering, 3(3): 127-141.

[10] Elchalakani, M., Zhao, X. L., and Grzebieta, R. H. (2002). "Bending tests to determine slenderness limits for cold-formed circular hollow sections". Journal of Constructional Steel Research, 58(11): 1407-1430.

[11] Jiao, H., and Zhao, X. L. (2004). "Section slenderness limits of very high strength circular steel tubes in bending". Thin-Walled Structures, 42(9): 1257-1271. 